\title{
Econometric Analysis of Landscape Preferences in Canterbury, New Zealand
}

\author{
P. Brown ${ }^{1}$ and C. Mortimer ${ }^{2}$ \\ ${ }^{1}$ Landcare Research, Lincoln 7608, New Zealand \\ ${ }^{2}$ Ministry of Business, Innovation, and Employment, Auckland 1143, New Zealand \\ Correspondence should be addressed to P. Brown; brownp@landcareresearch.co.nz
}

Received 28 April 2014; Accepted 8 July 2014; Published 17 August 2014

Academic Editor: Magda E. Kandil

Copyright (C) 2014 P. Brown and C. Mortimer. This is an open access article distributed under the Creative Commons Attribution License, which permits unrestricted use, distribution, and reproduction in any medium, provided the original work is properly cited.

The landscape of rural Canterbury, New Zealand, has evolved from tussock grasslands to one of the most productive dairying areas in the world. While these changes represent a boon for Canterbury's economy, the visual impact of land-use change has been dramatic. In this paper, we evaluate which changes to the Canterbury landscape have been most pronounced, how people react to those changes, which aspects of the rural landscape are of greatest importance to both urban and rural residents of Canterbury, and whether cost-effective means of mitigating visual changes to the landscape exist. We find that the majority of Cantabrians hold unfavourable views of recent changes to the landscape-particularly with regard to dairying-a finding that is consistent across both urban and rural survey respondents. Using a visual assessment study with cross-classified random effect, we find that dairy cows, irrigators, and silage bales significantly reduce viewers' subjective evaluations of landscapes while shelterbelts dramatically increase their subjective evaluations. Moreover, native New Zealand shelterbelts are preferred to exotic shelterbelts, but both are preferred to having no shelterbelts, suggesting that the negative visual impacts of dairy farming may be ameliorated by intensified tree planting.

\section{Introduction}

Agriculture represents a larger share of New Zealand's economy than that of any other OECD country except Turkey [1]. The agriculture, food, and forestry sectors generate $70 \%$ of New Zealand's merchandise export earnings and around $12 \%$ of gross domestic product. New Zealand is the world's largest dairy and sheep meat exporter [2]. Total exports are projected to grow over the next decade, led by agriculture [3], and the New Zealand government has announced a target of doubling agricultural exports by 2025 [2].

Famously, sheep in New Zealand once outnumbered people by a margin of 22 to 1 . However, falling wool prices, elimination of farming subsidies, and sustained droughts dramatically reduced the profitability of sheep farming, and the total number of sheep has fallen by $56 \%$ after peaking above 70 million in 1982 [4]. Consistent with models developed by Kerr and Hendy [5], dairy had displaced sheep and beef farming on higher quality agricultural land, driven largely by rapidly increasing demand from China. Between 1982 and 2012, the size of the national dairy herd more than doubled from 3 million to 6.1 million [6]. Dairy products alone now comprise $27 \%$ of the total value of New Zealand's exports, more than twice that derived from lamb and wool [7], and the dairy cooperative Fonterra, which is responsible for $30 \%$ of the world's dairy exports, has become New Zealand's single largest company.

Converting land use from grazing for sheep and other dry stock to dairy entails investing in dairy sheds, equipment, and, often, irrigation. These changes markedly affect the visual landscape by introducing buildings and machinery into paddocks, by altering the predominant livestock (e.g., from sheep to dairy cattle) and plant (e.g., from tussock to ryegrass) species and by replacing the dominant colour palette from dry browns to lush greens. Such changes are likely to be especially pronounced in Canterbury, New Zealand, which is dominated by high-quality pastoral land that was predominantly used for sheep and beef farming until 
the 1980s. Since 1982, Canterbury's dairy herd has increased by a staggering factor of $1639 \%$, from 69,000 dairy cattle to 1.2 million.

This paper is agnostic as to whether dairy intensification has positive or negative implications for Canterbury's environment. Instead, it seeks to uncover whether residents of Canterbury have noticed changes in the visual landscape associated with dairying and, if so, whether these changes are viewed positively or negatively by both urban and rural residents. The paper then uses a visual assessment study to quantify the hedonic change in landscape values associated with dairy conversion and proposes shelterbelts (plantations typically comprised one or more rows of trees or shrubs planted closely together in order to shelter livestock from wind and to protect soil from erosion, sometimes called "windbreaks") as one mean of restoring the innate scenic value of the Canterbury landscape.

We find that the majority of Cantabrians have noticed visual changes to the landscape and that the majority of those view them unfavourably. We further find strong consistency between rural and urban Cantabrians regarding preferences for the rural landscape. In particular, dairy cows, irrigators, silage bales, and overgrown road verges significantly reduce viewers' subjective evaluations of landscape images while shelterbelts significantly increase their subjective evaluations. Because the visual cues of dairying are seen negatively and because shelterbelts are shown to substantially mitigate these negative impacts, a further assessment is then undertaken to identify the preferred composition of shelterbelts; we find that shelterbelts comprised of native New Zealand trees are preferred to those comprised of exotics, although some exotic species are nevertheless viewed very favourably. Finally, we evaluate whether perceptions of various types of shelterbelts change with additional knowledge pertaining to the extent to which they promote biodiversity.

Section 2 describes the research methodology and Section 3 describes the Canterbury setting. Section 4 presents the results. Section 5 concludes.

\section{Canterbury, New Zealand}

With an area of $45,346 \mathrm{~km}^{2}$, Canterbury is New Zealand's largest region. The Conway River and the Southern Alps define its northern and western boundaries, and the southern border extends south of the Waitaki River; the Pacific Ocean traces its eastern edge. As of the 2013 census, the population of Canterbury stood at 539,546 [8], making it the most populous region on New Zealand's South Island and the second most populous region in the country. Some 341,469 (63\%) of Cantabrians reside in the Christchurch urban area, the third most populous urban area in New Zealand [8].

Like much of New Zealand, the landscape of Canterbury has undergone profound changes since the arrival of Māori settlers in the 13th century; fires destroyed much of the scrub and beech forests that originally dominated the landscape and tussock grassland slowly took over. In the nineteenth century, European settlers introduced exotic grasses, flowering plants, and trees that gradually supplanted much of the native vegetation. Canterbury's landscape has been further altered by economic activities such as livestock farming, cropping, forestry, and mining.

The modern Canterbury economy is a diversified mix of industrial activities-particularly business and property services, wholesale and retail trade, and manufacturing, all centred on Christchurch-and agriculture. The Canterbury Plains that surround Christchurch and extend south to the Otago border are well suited for moderately intensive livestock farming, particularly sheep farming. Indeed, during the height of New Zealand's sheep production in 1982, Canterbury had 12 million sheep, $17 \%$ of the national flock. Canterbury is also New Zealand's main producer of cereal crops, supplying roughly half of the wheat, barley, and oats [6].

However, dairying has largely supplanted other agricultural activities in Canterbury over the past three decades, and the number of sheep in Canterbury has fallen to 5.3 million while the number of dairy cattle increased from 69,000 to 1.2 million [6]. Today, nearly $20 \%$ of rural properties in Canterbury have at least some dairy and the median Canterbury dairy farm stocks 750 head of cattle on 210 hectares. Despite the fact that dairy now accounts for approximately $30 \%$ of New Zealand's export earnings and that the industry is estimated to have increased annual per capita income in Canterbury by NZ\$ 590 [1], many Cantabrians reportedly lament the resulting changes to Canterbury's iconic landscapes [9].

\section{Methodology}

Visual preference surveys are a common tool used to inform planning decisions. Following the protocol developed by Anton Nelessen, respondents subjectively evaluate a series of images. Each image is categorized by type, and means and standard deviations are calculated for each category in order to report which images-and hence which design features-are preferred, on average. This methodology has been championed by the new urbanist and smart growth movements, which have shown that the public prefers idyllic village scenes to contemporary suburban scenes [10-13] and has been used to justify long-range planning and changes in zoning ordinances (e.g., [14-16]). However, without additional analysis, it is unclear whether expressed preferences differ in a statistical sense, whether features for which we do not account influence results, and to which features of scenes viewers respond. Indeed, in the absence of such considerations, comparing means across scenes to inform planning may lead to decisions that may prove to be both costly and incorrect $[17,18]$.

Visual assessment studies, by contrast, undertake critical analyses of components depicted in images, allowing inferential statistics to test the strength and significance of differences across images while accounting for correlates over which planners have little control [19]. These studies have been used by progressive landscape architects, environmental psychologists, and urban planners to gauge public preference in a variety of contexts (e.g., [20-29]). 

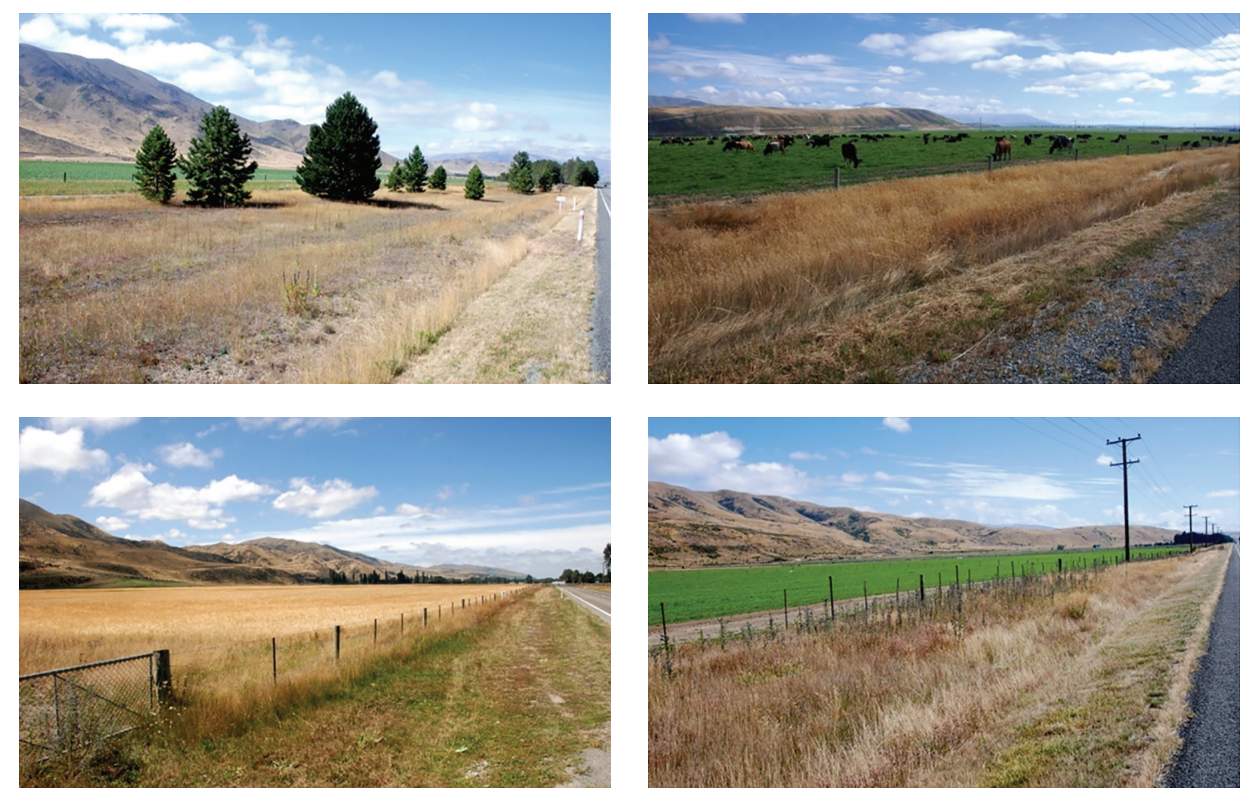

Figure 1: Diverse land-use and image content.

Best practice in visual assessment studies entails conducting a visual preference study in which respondents view between 5 and 100 images [30], often including several unevaluated "decoy images" at the beginning to allow for learning and calibration [31, 32]. Photographs are generally used, and efforts are made to ensure both the comparability (e.g., consistently using colour photographs shot under similar lighting conditions) and visual accuracy (e.g., by using wide-angle lenses) of image [33-35]. Results have been shown to be consistent when respondents rate images, rank images, or choose between paired images [36, 37]; with larger numbers of images, however, rating images on a Likert scale ranging from least preferred to most preferred is most efficient and feasible [38]. Finally, multivariate regression is used to explain differences in image content in a statistical sense (e.g., [39-41]).

Ordinary least squares (OLS) is the regression approach used in the vast majority of visual assessment studies. However, OLS assumes that each observation is independent; if this assumption is violated, for example, if the subjective evaluation of images is clustered by location, then OLS point estimates will be inefficient and their associated standard errors will be biased toward zero. Hierarchical modelling overcomes this limitation by introducing a "nesting" structure. For example, images in the present study are nested within respondents since each respondent evaluates the same set of images, and respondents are nested within images since each image is evaluated by the same group of respondents [42]. When an outcome varies systematically in two dimensions and random effects are present, the resulting data structure is best represented by a cross-classified random effects model, allowing random effects for both images and respondents to be used $[43,44]$.

To ensure that images used in the visual assessment study were consistent in terms of angle, perspective, lighting, and exposure, a photographer drove $900 \mathrm{~km}$ of rural roads throughout Canterbury, photographing approximately 1200 scenes under similar weather and lighting conditions and from a similar perspective. These 1200 scenes were categorised by geography, land use, and image content, and 43 images were selected for the study based on these characteristics as well as comparability of photographic attributes. For example, the four images depicted in Figure 1 represent diverse land use and image content while sharing similar angle, perspective, lighting, and exposure. The images depicted in Figure 2 similarly show different types of shelterbelts shown under similar conditions. The exposure, contrast, saturation, and temperature of each of the images were then evaluated by an independent consultant to ensure comparability and to reduce concerns about bias stemming from photo warmth and quality [37].

The selected images were shown to two focus groups, participants of which identified the key features depicted in scene. A committee of independent researchers then categorised the content of each of the 43 images according to the 14 features identified in the focus groups using the Delphi method $[45,46]$ to derive consensus. These features are listed in Table 1.

While individual landowners have little or no influence over the last two variables, they were included because the presence of telephone and electricity poles and variation in topography may affect the aesthetic quality (and hence viewers' perceptions) of images of Canterbury's landscape.

A survey was administered to 800 residents of Canterbury via the Internet in March 2012. The Canterbury population was stratified by urban/rural residence for sampling. Within each stratum, potential respondents were selected at random from a population of individuals who agreed to participate in online survey research and who were at least 18 years old at the time of the survey. Importantly, this population was recruited via telephone and other non-Internet sources, reducing the potential sample selection biases inherent in online surveys 

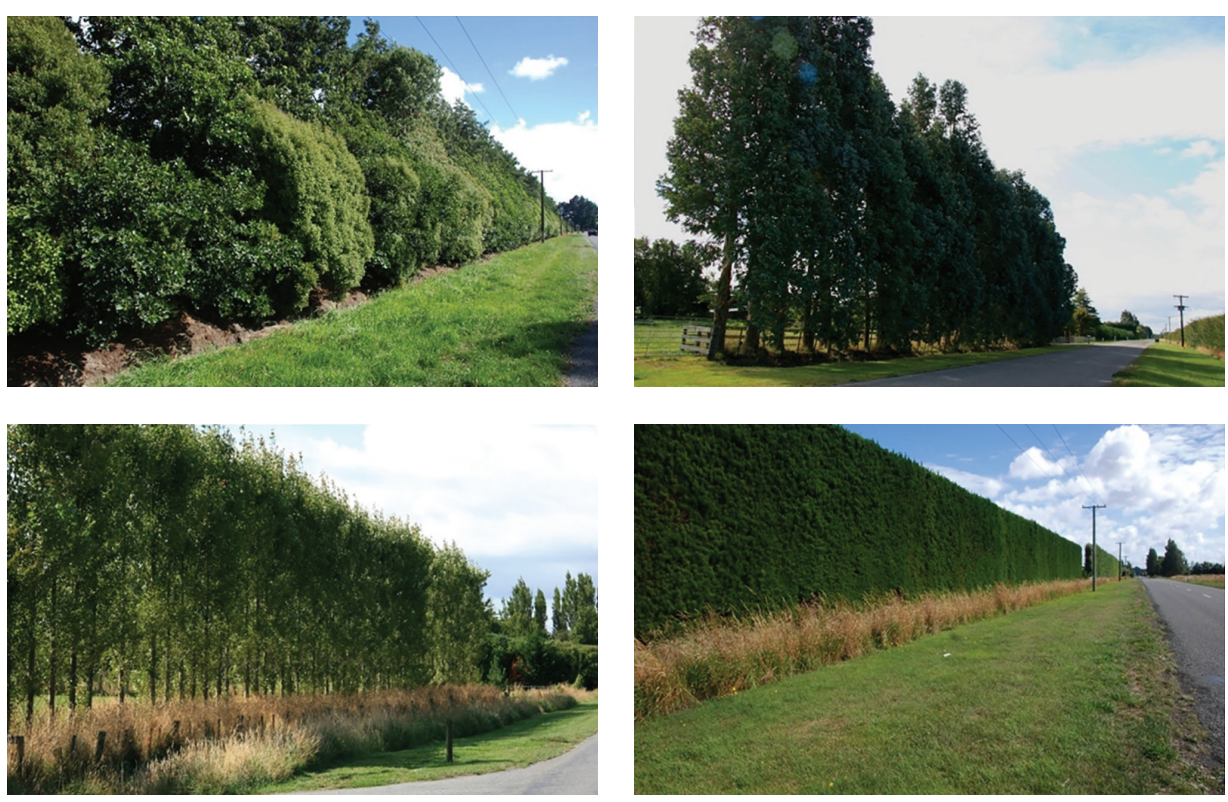

FIgURE 2: Types of shelterbelts.

TABLE 1: Image components of the photos used in the visual assessment survey.

\begin{tabular}{|c|c|}
\hline Component & Categorisation \\
\hline Roadside shelterbelt in image & Yes, no \\
\hline Shelterbelt origin & None, native, and exotic \\
\hline Shelterbelt species & $\begin{array}{l}\text { None, poplar, gum, gorse, pine, } \\
\text { macrocarpa, Pittosporum, flax, } \\
\text { and mixed native trees }\end{array}$ \\
\hline Shelterbelt shape & None, trimmed, and untrimmed \\
\hline Shelterbelt height & None, short, and tall \\
\hline Distant shelterbelt & Yes, no \\
\hline Prominent individual trees & Yes, no \\
\hline Type of stock & $\begin{array}{l}\text { None, sheep, beef cattle, and } \\
\text { dairy cows }\end{array}$ \\
\hline Prominent horticulture & Yes, no \\
\hline Prominent irrigator & Yes, no \\
\hline Prominent silage bales & Yes, no \\
\hline Prominent green paddocks & Yes, no \\
\hline Prominent weeds & Yes, no \\
\hline Overgrown verge & Yes, no \\
\hline $\begin{array}{l}\text { Prominent electric/telephone } \\
\text { poles }\end{array}$ & Yes, no \\
\hline Prominent hills & Yes, no \\
\hline
\end{tabular}

[47]. Consistent with the population distribution of Canterbury, $67 \%$ of the sample was drawn from urban centres.

The survey covered household demographics, occupations, and hobbies of household members, perceptions about the importance of various industrial sectors for Canterbury's economic future, perceptions of different rural land-use changes, and the visual preference component described above. Apart from the visual preference component, the entire survey comprised closed-ended, multiple-choice questions. This format was chosen to facilitate efficiency and comparability of survey responses and is standard in quantitative survey research [48]. For the visual preference component of the survey, respondents were asked to evaluate the landscape depicted on a 7-point Likert scale that ranged from extremely unappealing (low scores) to extremely appealing (high scores). Five decoy images were included at the beginning to allow for learning and calibration; after these images were shown, images appeared in random order to circumvent biases arising from viewing order. The survey was extensively tested for understanding prior to administration.

Sixty responses were eliminated due to inconsistency and/or poor quality (e.g., spending too little time on survey questions), leaving an effective sample of 740 . The responses that were omitted did not follow systematic patterns; for example, no demographic group was disproportionately represented in the rejected surveys. Moreover, the results shown below are substantively unchanged using the entire sample of 800 .

Summary statistics for the sample are presented in Table 2 . The mean age of survey respondents was 50 , while the youngest and oldest respondents were 19 and 88 , respectively. The average age of adult residents in Canterbury in 2006 was 48.3 [49], although there is some evidence that three large earthquakes centred near Christchurch in 2010 and 2011 disproportionately induced migration among young people [50]. Hence, the age structure of our sample reflects that of the Canterbury population. The mean duration of residence in Canterbury is 31 years. Half of the sample is male, as expected, although just $4.5 \%$ of the respondents identify themselves as being Māori as opposed to non-Māori New Zealanders and other ethnicities, approximately 2.5 percentage points lower than the Canterbury population in general. 
TABLE 2: Summary statistics.

\begin{tabular}{|c|c|c|c|c|c|c|c|c|}
\hline \multirow{2}{*}{ Variable } & & \multicolumn{2}{|c|}{ Total } & \multicolumn{2}{|c|}{ Rural } & \multicolumn{2}{|c|}{ Urban } & \multirow{2}{*}{ Difference } \\
\hline & & Mean & Std. dev. & Mean & Std. dev. & Mean & Std. dev. & \\
\hline Male & Dummy & 0.49 & 0.50 & 0.51 & 0.50 & 0.47 & 0.50 & \\
\hline Age & Years & 50.31 & 14.71 & 51.20 & 13.74 & 49.86 & 15.16 & \\
\hline Non-Māori NZ’er & Dummy & 0.83 & 0.38 & 0.86 & 0.35 & 0.82 & 0.39 & \\
\hline Māori NZ & Dummy & 0.05 & 0.21 & 0.033 & 0.18 & 0.051 & 0.22 & \\
\hline Other ethnicity & Dummy & 0.11 & 0.32 & 0.11 & 0.31 & 0.12 & 0.32 & \\
\hline Canterbury residency & Years & 31.15 & 19.20 & 31 & 19.65 & 31.28 & 18.98 & \\
\hline Farm household & Dummy & 0.081 & 0.27 & 0.17 & 0.38 & 0.034 & 0.19 & $* * *$ \\
\hline Outdoors activities & Dummy & 0.81 & 0.39 & 0.89 & 0.31 & 0.77 & 0.42 & $* * *$ \\
\hline$N$ & & \multicolumn{2}{|c|}{740} & \multicolumn{2}{|c|}{245} & \multicolumn{2}{|c|}{495} & \\
\hline
\end{tabular}

Notes: rural-urban differences: ${ }^{* * *}$ significant at $1 \%$ level; ${ }^{* *}$ significant at $5 \%$ level; ${ }^{*}$ significant at $10 \%$ level.

Gender, age, residency, and ethnicity are statistically indistinguishable for the rural and urban portions of the sample. In contrast, rural respondents are more than twice as likely as urban respondents to be employed in the farming sector or to have immediate family members who are employed in that sector, a difference that is statistically significant at the $1 \%$ level. Rural respondents are also significantly more likely to participate in outdoors activities such as hiking/tramping, camping, hunting, bird watching, and boating at least once per year. For these reasons and because rural and urban people may hold differing views on Canterbury's rural landscape, we split the sample into urban and rural subsamples in the analysis.

\section{Results}

This section comprises four distinct parts. First, we use survey data to identify industrial sectors that are considered most important for the Canterbury economy. We then report on perceptions of changes to Canterbury's rural landscape, focusing particularly on those associated with dairying, and then assess how the perceived economic importance of dairying affects these views. Next, we identify landscape images that were most and least favoured by respondents and evaluate them to quantify the contribution of each component in the image using a cross-clustered random effects model. Finally, because shelterbelts are strongly associated with higher subjective evaluations of landscape images, we explore whether preferences for biodiversity influences preferences for specific types of shelterbelts.

4.1. Industrial Sectors and the Canterbury Economy. Survey results indicate that rural residents are $96 \%$ more likely than urban residents to identify dairy as being one of the two most important sectors for Canterbury's economy (a difference that is statistically significant at the $1 \%$ level) (Figure 3). Similarly, rural residents are $40 \%$ more likely than urban residents to identify raising sheep and/or beef as being one of the two most important sectors for Canterbury's economy (significant at the $1 \%$ level). In contrast, urban residents are $33 \%$ more likely than rural residents to identify tourism and 32\% more likely than rural residents to identify

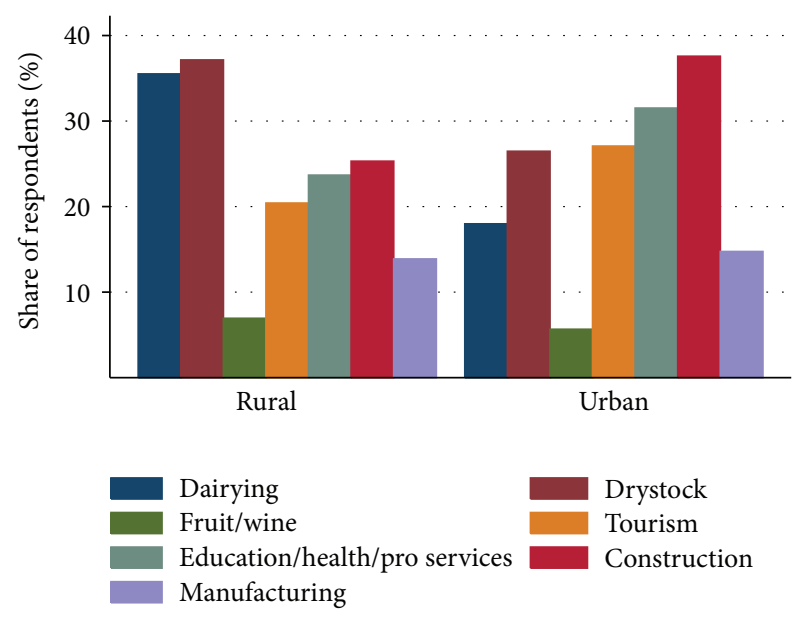

FIGURE 3: Industrial sectors that are considered most important for the Canterbury economy.

education, health, and professional services as being among the two most important sectors for Canterbury's economy, respectively (significant at the 5\% level). Urban residents are also $48 \%$ more likely than rural residents to identify construction as being one of the two most important sectors for New Zealand's economy (significant at the 1\% level), consistent with the urban recovery efforts following the 2010 and 2011 earthquakes centred in and around Christchurch. However, urban and rural residents are equally likely to identify fruit/wine production and manufacturing as being among the two most important sectors for Canterbury's economy. Other sectors, including wholesale/retail trade; other livestock production; forestry, fishing, and hunting; government and safety; and legal, scientific, and technical services were identified as being central to Canterbury's economy by fewer than $5 \%$ of survey respondents.

4.2. Changes to the Visual Landscape and How They Are Perceived. $83 \%$ of survey respondents who lived in Canterbury for more than 3 years noted changes in the rural Canterbury landscape in recent years. Among them, $71 \%$ identified dairy conversion as being either the largest or the second-largest 


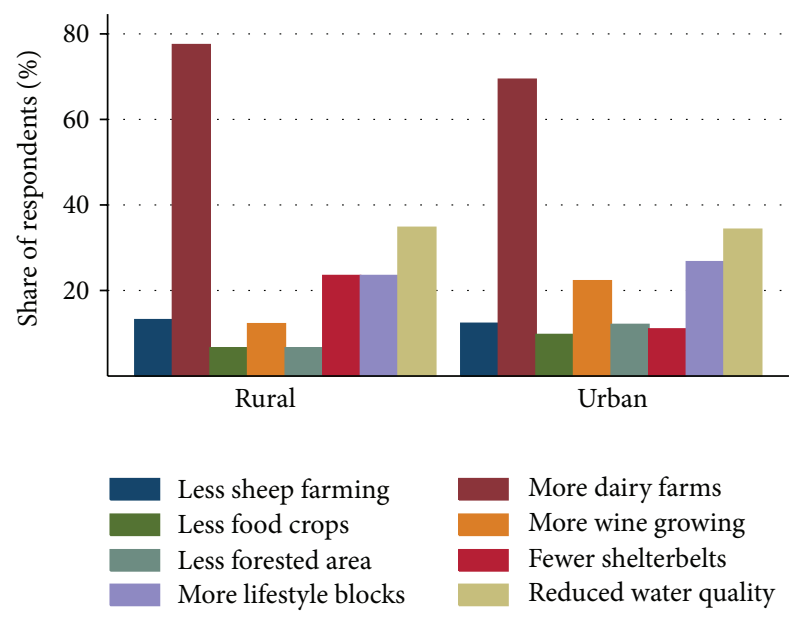

FIgURE 4: Noted changes in the visual landscape.

change (Figure 4), with similar reporting among rural and urban residents. The next most commonly noted change in the Canterbury landscape is reduced water quality, which approximately $38 \%$ of respondents reported (see also [51]); as with dairy conversion, reduced water quality was noted by similar shares of rural and urban residents. More lifestyle blocks and less sheep farming were the third and fourth most frequently reported changes, respectively.

As shown in Figure 5, rural survey respondents who reported dairy conversion as one of the two largest visual changes in Canterbury are 55\% more likely than their urban counterparts to view those changes favourably (significant at the 5\% level). Urban residents who reported dairy conversion as one of the two largest visual changes in Canterbury are $22 \%$ more likely than their rural counterparts to view those changes unfavourably (significant at the $10 \%$ level). That is, rural people are significantly more likely to view dairy conversion positively and significantly less likely to view it negatively.

A probit model was used to identify characteristics of respondents who hold a negative view of the visual impact of dairy conversion (defined as both identifying dairy conversion as being among the two most notable changes to the Canterbury landscape and reporting that they view these changes negatively), with particular attention paid to the perceived importance of dairying for the Canterbury economy. Marginal effects and heteroskedasticity-robust standard errors are reported in Table 3.

People who believe that dairy is one of the two most important sectors for the Canterbury economy are about $27 \%$ less likely to perceive the visual impacts of dairy conversion negatively, ceteris paribus. This result is statistically significant at the $1 \%$ level, and the magnitude of the impact is similar for rural and urban residents. Gender, ethnicity, and occupation do not affect the likelihood that survey respondents view the visual impacts of dairy conversion negatively, but urban residents who regularly participate in outdoors activities are $12 \%$ more likely than urban residents who do not participate in outdoors activities to view the visual impacts of dairy conversion negatively, ceteris paribus.

4.3. Quantitative Evaluation of the Visual Landscape. This section examines participant responses to the 43 images included in the quantitative survey. Urban and rural residents show similar preferences for the visual rural landscape; four of the five most favourable images (Figure 6) and all of the five least favourable images (Figure 7) are identical for urban and rural survey respondents.

As described in Section 3, a visual assessment study was used to quantify the marginal effects of image components listed in Table 1 on survey respondents' subjective evaluations of each image. A cross-classified random effects model [43] was used to account for random effects in both images and viewers [42]. Point estimates and standard errors are reported in Table 4.

Consistent with the literature on visual assessment, the point estimates on many image components are large in magnitude and statistically significant, both individually and in combination. For example, images with roadside shelterbelts score $0.62-0.73$ points higher on the 7-point Likert scale relative to identical images with no shelterbelt, ceteris paribus. This effect is large-larger, in fact, than the effect of any other image component-and rural and urban people agree in this regard. Distant shelterbelts (i.e., shelterbelts that do not front roadsides), individual trees, and horticulture also increase the subjective evaluation of the visual landscape for both groups. In contrast, irrigators, silage bales, and overgrown verges significantly detract from perceptions of the visual landscape, with irrigators reducing the ratings assigned to images by $0.86-0.91$ points.

Interestingly, the subjective evaluation of images that include sheep is higher for both urban and rural people while the subjective evaluation of images that depict dairy cows is lower for both groups. However, urban and rural residents split on beef cattle; the presence of beef cattle does not affect the score assigned to images for the rural sample, but it negatively affects the score for the urban sample. One possible explanation is that most survey respondents dislike seeing dairy cows but that urban residents have a harder time distinguishing between dairy cows and beef cattle (prominent weeds do not significantly impact the visual assessment of images for either rural or urban residents, and this variable has been omitted for the sake of parsimony. The simple correlation between prominent green paddocks and image score is negative, suggesting that green paddocks are disliked by survey respondents. However, green paddocks are highly collinear with irrigators and dairy cows, complicating interpretation of results when this variable is included in the multivariate regression. Hence, this variable too has been omitted from the quantitative results).

Stamps [52] and Regen and Horn [53] show that most heterogeneity in subjective evaluation scores stem from differences in image characteristics rather than differences in viewer characteristics. Hence, it is not surprising that images are evaluated similarly by men and women, people of different ethnicities, newcomers and long-term residents, 


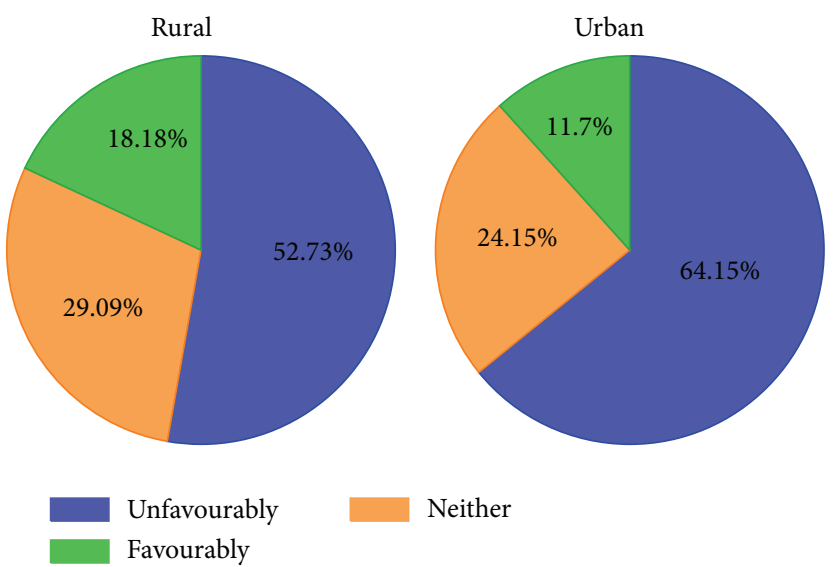

FIGURE 5: Views on the visual changes associated with dairy, among those who identify dairy as one of two largest changes.

TABLE 3: Determinants of negative view of visual impact of dairy conversion.

\begin{tabular}{|c|c|c|c|c|c|}
\hline \multirow{2}{*}{ Variable } & \multirow{2}{*}{ Unit } & \multicolumn{2}{|c|}{ Rural residents } & \multicolumn{2}{|c|}{ Urban residents } \\
\hline & & $\mathrm{d} y / \mathrm{d} x$ & $z$ & $\mathrm{~d} y / \mathrm{d} x$ & $z$ \\
\hline Believes that dairy is important for economy & Dummy & $-0.26^{* * *}$ & $(0.00)$ & $-0.28^{* * *}$ & $(0.00)$ \\
\hline Male & Dummy & -0.059 & $(0.39)$ & -0.026 & $(0.59)$ \\
\hline Age & Years & -0.0040 & $(0.14)$ & $0.0062^{* * *}$ & $(0.00)$ \\
\hline Non-Māori NZ’er & Dummy & 0.009 & $(0.94)$ & 0.033 & $(0.65)$ \\
\hline Māori & Dummy & -0.11 & $(0.54)$ & 0.08 & $(0.52)$ \\
\hline Canterbury residency & Years & 0.0021 & $(0.32)$ & 0.0004 & $(0.80)$ \\
\hline Farm family & Dummy & -0.078 & $(0.36)$ & -0.022 & $(0.88)$ \\
\hline Outdoors activities & Dummy & -0.18 & $(0.13)$ & $0.12^{* *}$ & $(2.50)$ \\
\hline$N$ & \multicolumn{3}{|c|}{237} & \multicolumn{2}{|c|}{475} \\
\hline
\end{tabular}

Notes: estimated with a probit model. Additional controls for area of residency and travel patterns are included but not reported. Marginal effects reported. $Z$ statistics based on heteroskedasticity-robust standard errors reported in parentheses. ${ }^{* * *}$ Significant at the $1 \%$ level; ${ }^{* *}$ significant at the $5 \%$ level; ${ }^{*}$ significant at the $10 \%$ level. "Negative view" is defined as identifying dairy as being one of two largest changes and stating that the changes are negative.
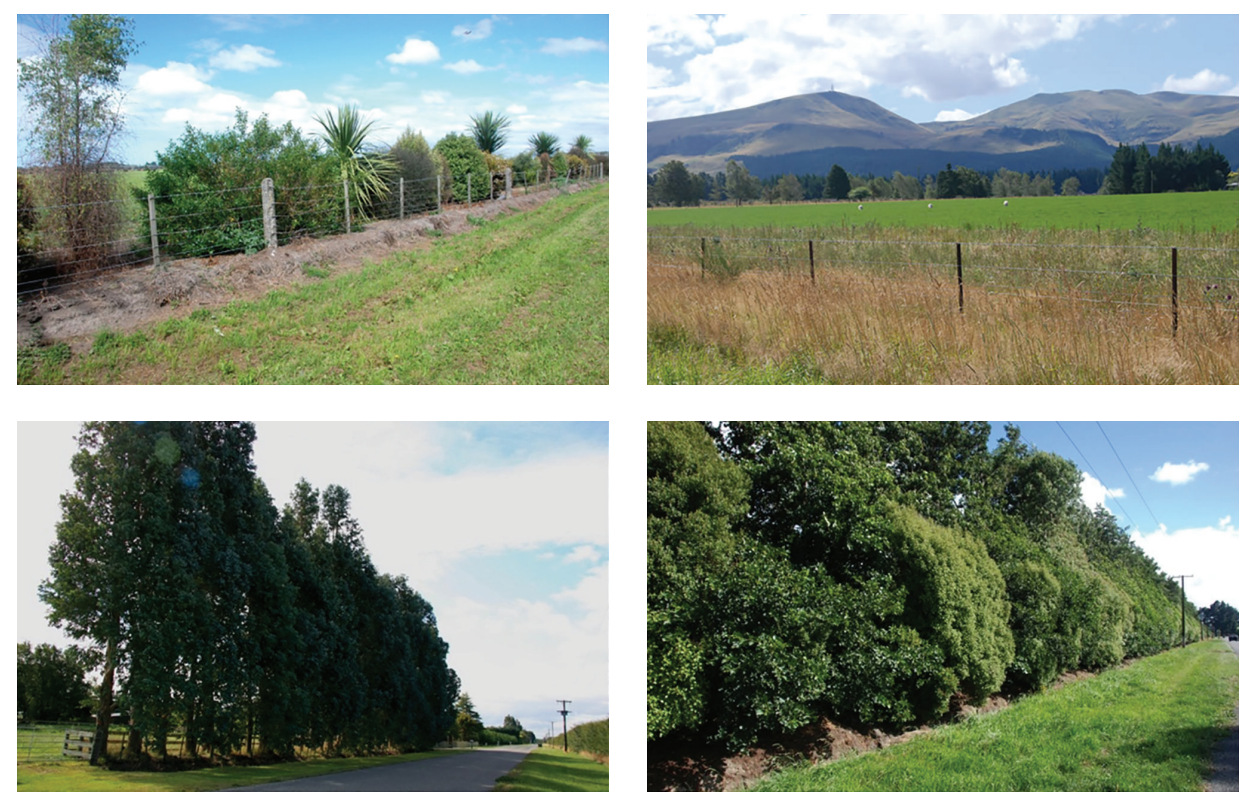

FIGURE 6: Four most favourable images in the survey. 

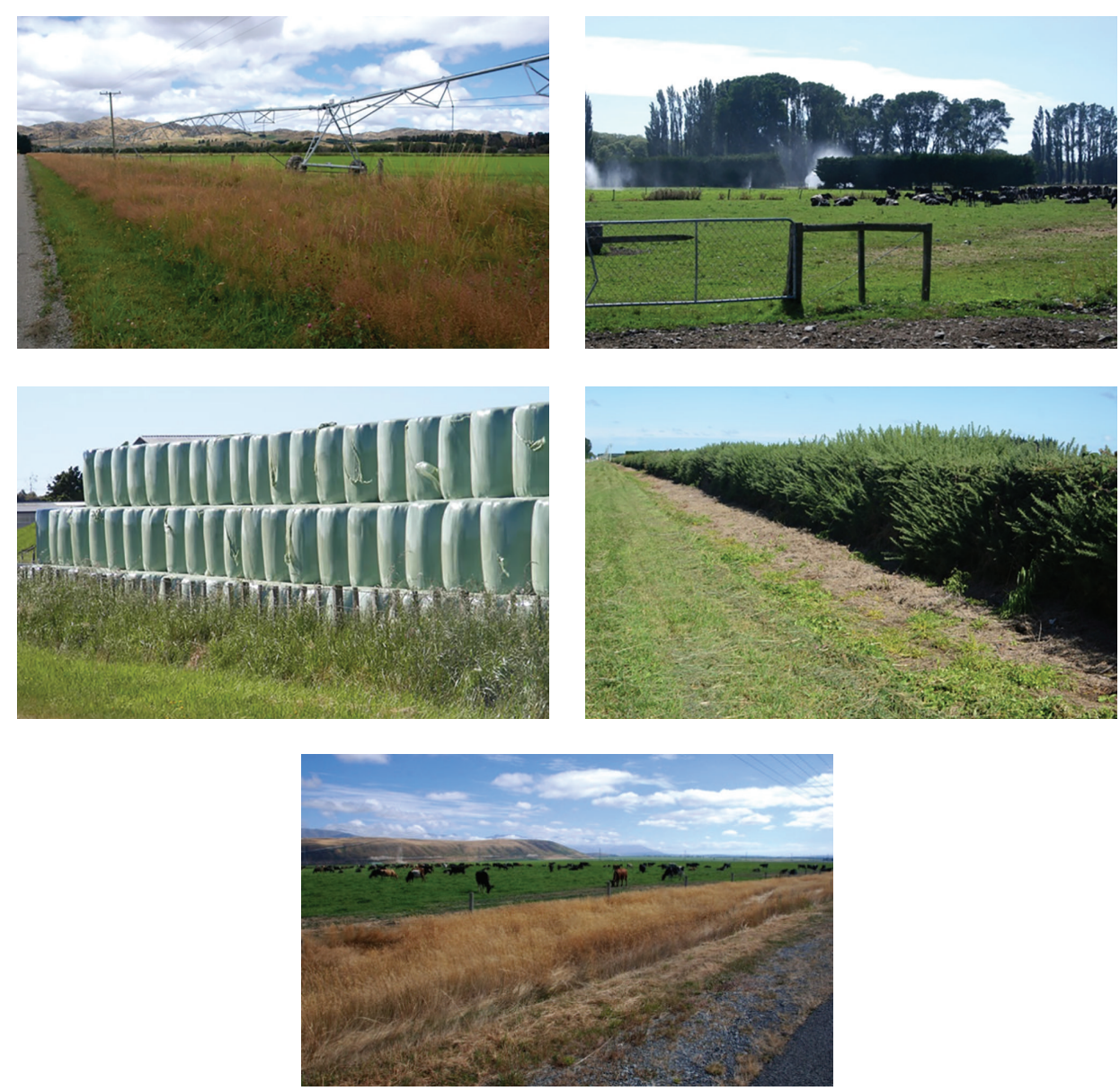

FIGURE 7: Five least favourable images in the survey.

farm and nonfarm families, outdoors enthusiasts, and others. That being said, older rural residents rated images slightly higher than younger urban residents, and urban Māori rated images 0.31 points lower than other urban residents, ceteris paribus, underscoring the importance of controlling for viewer effects. In addition, prominent telephone and electricity poles lower the subjective score assigned to images while prominent hills raise the scores. As noted above, individual landowners have little control over such factors, but the statistical significance of these variables underscores the importance of controlling for potential correlates of image score in a multivariate regression framework.

Given the strong, positive effect of shelterbelts on viewers' subjective evaluations of the rural landscape and the ability of shelterbelts to mitigate the visual impact of irrigators, silage bales, and other less favourable components, a crossclassified random effects model was estimated with different categorisations of shelterbelts. Results are shown in Tables 5 and 6; although the same set of control variables was included in these estimates, results were nearly identical and the point estimates are suppressed for the sake of parsimony.

Table 5 shows that while exotic and native shelterbelts are both preferred to no shelterbelts, native shelterbelts are strongly preferred by both rural and urban people. Specifically, images with native shelterbelts score 0.29 points higher on the 7-point Likert scale than images with exotic shelterbelts (which in turn score 0.24 points higher than those without shelterbelts) among urban respondents, ceteris paribus (significant at the $1 \%$ level); images with native shelterbelts score 0.35 points higher than images with exotic shelterbelts for rural people, ceteris paribus (significant at the $1 \%$ level).

Respondents also have strong preferences for different species of plants and shrubs in shelterbelts. Specifically, images with shelterbelts comprised of gum trees score 1.26 and 1.14 points higher than images without shelterbelts for rural and urban respondents, respectively, ceteris paribus (significant at the 1\% level). Images with shelterbelts comprising mixed native trees score 1.21 and 1.07 points higher than images without shelterbelts. The least favoured types of shelterbelts are gorse hedgerows and pine trees; images with gorse hedgerows score $0.35-0.53$ points lower than images without shelterbelts while those with pine shelterbelts score $0.27-0.35$ points higher than those without shelterbelts.

4.4. Biodiversity and Shelterbelt Options. At the conclusion of the survey, participants were asked to reevaluate the four images depicted in Figure 8 after being given additional information pertaining to their biodiversity values. The first 
TABLE 4: Visual assessment study.

\begin{tabular}{|c|c|c|c|c|c|}
\hline \multirow{2}{*}{ Variable } & \multirow{2}{*}{ Unit } & \multicolumn{2}{|c|}{ Rural } & \multicolumn{2}{|c|}{ Urban } \\
\hline & & Estimate & Std. err. & Estimate & Std. err. \\
\hline Shelterbelt in image & Dummy & $0.73^{* * *}$ & $(0.051)$ & $0.62^{* * *}$ & $(0.035)$ \\
\hline Distant shelterbelt & Dummy & $0.34^{* * *}$ & $(0.038)$ & $0.36^{* * *}$ & $(0.026)$ \\
\hline Individual trees & Dummy & $0.19^{* * *}$ & $(0.037)$ & $0.14^{* * *}$ & $(0.025)$ \\
\hline Sheep & Dummy & $0.62^{* * *}$ & $(0.056)$ & $0.46^{* * *}$ & $(0.038)$ \\
\hline Beef cattle & Dummy & -0.0032 & $(0.056)$ & $-0.089^{* *}$ & $(0.038)$ \\
\hline Dairy cows & Dummy & $-0.34^{* * *}$ & $(0.044)$ & $-0.28^{* * *}$ & $(0.030)$ \\
\hline Horticulture & Dummy & $0.38^{* * *}$ & $(0.038)$ & $0.25^{* * *}$ & $(0.026)$ \\
\hline Irrigator & Dummy & $-0.91^{* * *}$ & $(0.050)$ & $-0.86^{* * *}$ & $(0.034)$ \\
\hline Silage bales & Dummy & $-0.33^{* * *}$ & $(0.050)$ & $-0.33^{* * *}$ & $(0.034)$ \\
\hline Overgrown verge & Dummy & $-0.15^{* * *}$ & $(0.030)$ & $-0.14^{* * *}$ & $(0.020)$ \\
\hline Electric/telephone poles & Dummy & -0.035 & $(0.031)$ & $-0.037^{*}$ & $(0.021)$ \\
\hline Hills & Dummy & $0.11^{* * *}$ & $(0.032)$ & $0.074^{* * *}$ & $(0.022)$ \\
\hline Male & Dummy & -0.0087 & $(0.080)$ & 0.036 & $(0.063)$ \\
\hline Age & Years & $0.0081^{* *}$ & $(0.0033)$ & 0.00021 & $(0.0025)$ \\
\hline Non-Māori NZ’er & Dummy & -0.056 & $(0.13)$ & -0.15 & $(0.095)$ \\
\hline Māori & Dummy & -0.10 & $(0.26)$ & $-0.31^{*}$ & $(0.16)$ \\
\hline Canterbury residency & Years & -0.00019 & $(0.0024)$ & 0.0016 & $(0.0020)$ \\
\hline Farm family & Dummy & 0.095 & $(0.11)$ & 0.039 & $(0.16)$ \\
\hline Outdoors activities & Dummy & 0.025 & $(0.13)$ & -0.046 & $(0.074)$ \\
\hline Constant & & -0.082 & $(0.25)$ & $0.41^{* * *}$ & $(0.15)$ \\
\hline Number of groups & & & & & \\
\hline Obs. per group & & & & & \\
\hline
\end{tabular}

Notes: Maximum likelihood model estimated using cross-classified random effects. Standard errors reported in parentheses. ${ }^{* * *}$ Significant at the $1 \%$ level; ${ }^{* * *}$ significant at the $5 \%$ level; * ${ }^{*}$ significant at the $10 \%$ level.

TABLE 5: Visual assessment study with shelterbelt origin.

\begin{tabular}{|c|c|c|c|c|c|}
\hline \multirow{2}{*}{ Variable } & \multirow{2}{*}{ Unit } & \multicolumn{2}{|c|}{ Rural } & \multicolumn{2}{|c|}{ Urban } \\
\hline & & Estimate & Std. err. & Estimate & Std. err. \\
\hline Exotic shelterbelt & Dummy & $0.34^{* * *}$ & $(0.045)$ & $0.24^{* * *}$ & $(0.031)$ \\
\hline Native shelterbelt & Dummy & $0.69^{* * *}$ & $(0.052)$ & $0.53^{* * *}$ & $(0.035)$ \\
\hline Number of groups & & \multicolumn{2}{|c|}{244} & \multicolumn{2}{|c|}{494} \\
\hline Observations per group & & \multicolumn{2}{|c|}{38} & \multicolumn{2}{|c|}{38} \\
\hline
\end{tabular}

Notes: Maximum likelihood model estimated using cross-classified random effects. Standard errors reported in parentheses. ${ }^{* * *}$ Significant at the $1 \%$ level; ${ }^{* *}$ significant at the $5 \%$ level; ${ }^{*}$ significant at the $10 \%$ level.

TABLE 6: Visual assessment study with shelterbelt types.

\begin{tabular}{|c|c|c|c|c|c|}
\hline \multirow{2}{*}{ Variable } & \multirow{2}{*}{ Unit } & \multicolumn{2}{|c|}{ Rural } & \multicolumn{2}{|c|}{ Urban } \\
\hline & & Estimate & Std. err. & Estimate & Std. err. \\
\hline Poplar shelterbelt & Dummy & $1.11^{* * * *}$ & $(0.089)$ & $1.08^{* * *}$ & $(0.061)$ \\
\hline Gum shelterbelt & Dummy & $1.26^{* * *}$ & $(0.089)$ & $1.14^{* * *}$ & $(0.061)$ \\
\hline Gorse shelterbelt & Dummy & $-0.53^{* * *}$ & $(0.10)$ & $-0.35^{* * *}$ & $(0.065)$ \\
\hline Pine shelterbelt & Dummy & $0.35^{* * *}$ & $(0.066)$ & $0.27^{* * *}$ & $(0.045)$ \\
\hline macrocarpa shelterbelt & Dummy & $0.88^{* * *}$ & $(0.089)$ & $0.69^{* * *}$ & $(0.061)$ \\
\hline Pittosporum shelterbelt & Dummy & $0.71^{* * *}$ & $(0.089)$ & $0.42^{* * *}$ & $(0.061)$ \\
\hline Flax shelterbelt & Dummy & $0.62^{* * *}$ & $(0.089)$ & $0.64^{* * *}$ & $(0.061)$ \\
\hline Mixed native shelterbelt & Dummy & $1.21^{* * *}$ & $(0.075)$ & $1.07^{* * *}$ & $(0.051)$ \\
\hline Number of groups & & \multicolumn{2}{|c|}{244} & \multicolumn{2}{|c|}{494} \\
\hline Obs. per group & & \multicolumn{2}{|c|}{38} & \multicolumn{2}{|c|}{38} \\
\hline
\end{tabular}

Notes: maximum likelihood model estimated using cross-classified random effects. Standard errors reported in parentheses. ${ }^{* * *}$ Significant at the $1 \%$ level; ${ }^{* *}$ significant at the $5 \%$ level; ${ }^{*}$ significant at the $10 \%$ level. 

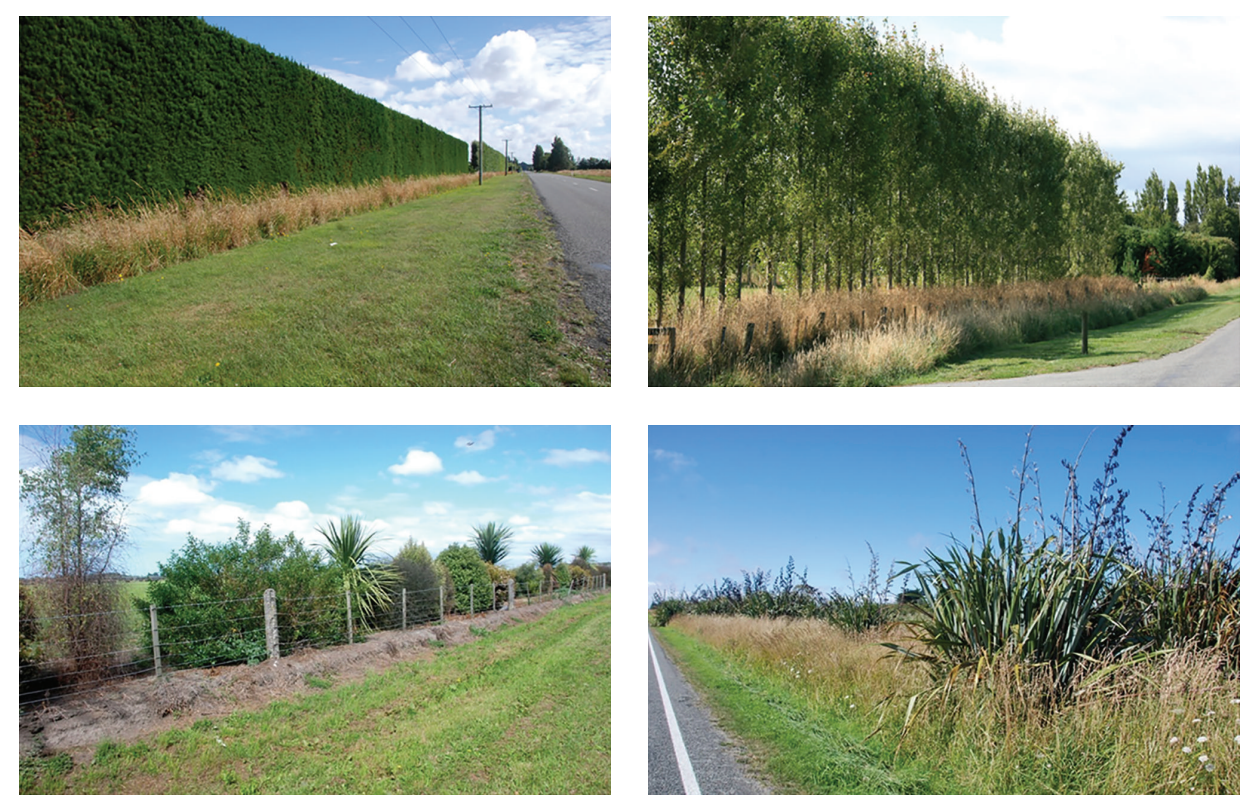

FIGURE 8: Images used in biodiversity assessment. From top left, going clockwise: macrocarpa with a medium biodiversity value; poplar with a low biodiversity value; flax with a high biodiversity value; and mixed native with a very high biodiversity value.

image featured a macrocarpa shelterbelt, which has a medium biodiversity value; like the first five images included in the visual preference survey, it was used primarily for learning and calibration. The second and third images featured poplar and flax shelterbelts, which have low and moderately high biodiversity values, respectively. The final image depicted a shelterbelt comprising mixed native trees, including Pittosporum, cabbage trees, Caprosma, and ribbonwood; the biodiversity value of this shelterbelt is very high.

Given additional knowledge regarding biodiversity, poplar shelterbelts become less attractive for approximately $38 \%$ of survey respondents (Figure 9), although urban respondents are $27 \%$ more likely than rural respondents to assign lower scores to images featuring poplar shelterbelts (significant at the $5 \%$ level). Approximately $40 \%$ of respondents report finding flax more attractive and approximately $58 \%$ of respondents report finding mixed native shelterbelts more attractive after learning about their respective biodiversity values. Interestingly, differences in the point estimates for flax and mixed natives are not statistically significant at the $10 \%$ level; that is, urban and rural residents are equally likely to find flax and mixed natives more attractive, given additional knowledge regarding biodiversity.

\section{Conclusion}

The number of dairy cattle in Canterbury, New Zealand, has increased by more than $1600 \%$ in the last 30 years. Dairy conversion and intensification have been an economic boon to the region, but irrigators, silage, feed pads, and lush paddocks have significantly altered the rural landscape. Survey results show that the majority of Canterbury residents have noticed such changes to the rural landscape and that

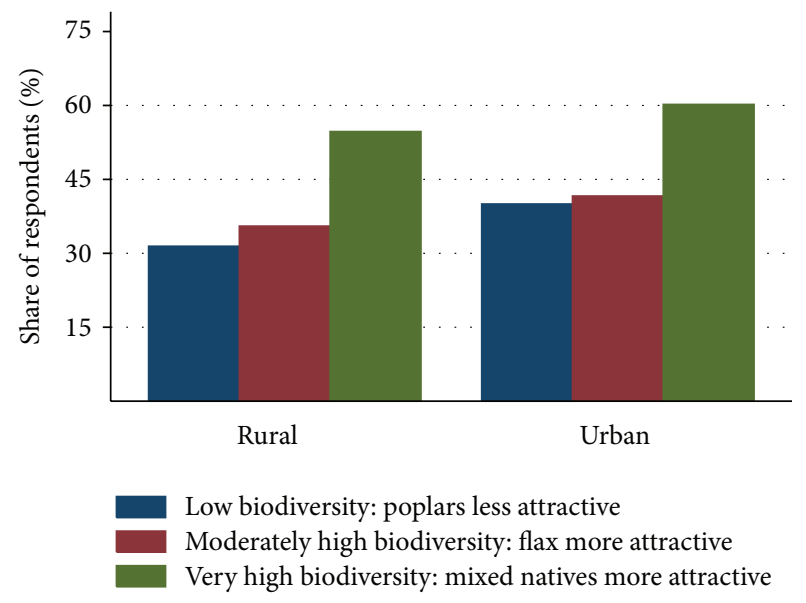

FIGURE 9: Biodiversity values and the relative attractiveness of shelterbelt options.

the majority view those changes unfavourably. This finding provides evidence to support the adoption of land practices and public policies to mitigate negative visual changes and to restore the hedonic value of Canterbury's rural landscape.

Using cross-classified random effects methods in a visual assessment study, we show that urban and rural Cantabrians are consistent in the features of the rural landscape that they dislike and the features that they prefer. Specifically, a roadside shelterbelt in the survey image offsets any other feature, including irrigators, dairy cows, and silage bales, all of which are viewed decidedly negatively. Indeed, the single highest rated image included in the survey depicts a mixed native shelterbelt screening a working dairy farm. Residents also respond positively to shelterbelts in the distance and to individual trees. 
Finally, the survey results show that Canterbury residents prefer mixed native shelterbelts and that this preference increases when respondents are made aware of their high biodiversity value. Developing policy to encourage farmers to plant mixed native shelterbelts can, therefore, meet two objectives: improving the visual landscape of Canterbury and increasing biodiversity on farms.

\section{Conflict of Interests}

The authors declare that there is no conflict of interests regarding the publication of this paper.

\section{References}

[1] NZIER, "Dairy's Role in Sustaining New Zealand," Report, 2010, https://nzier.org.nz/publications/dairys-role-in-sustaining-newzealand.

[2] Ministry of Primary Industries, "Situation and outlook for primary industries," 2013, http://www.mpi.govt.nz/news-resources/news/situation-amp-outlook-for-primary-industries.

[3] "OECD/Food and Agricultural Organisation of the United Nations," OECD-FAO Agricultural Outlook, OECD Publishing, Paris, France, 2013.

[4] Statistics New Zealand, "New Zealand is Home to 3 Million People and 60 Million Sheep," 2012, http://www.stats.govt.nz/ browse_for_stats/population/mythbusters/3million-people60million-sheep.aspx.

[5] S. Kerr and J. Hendy, "Drivers of rural land use in New Zealand: estimates from national data," Working Paper MEL 0368, Motu Economic and Public Policy Research, 2004.

[6] Statistics New Zealand, "Agricultural Census 2012," http://www .stats.govt.nz/browse_for_stats/industry_sectors/agriculturehorticulture-forestry/2012-agricultural-census-tables.aspx.

[7] Statistics New Zealand, "New Zealand Official Yearbook 2012," 2013, http://www.stats. govt.nz/yearbook2012.

[8] Statistics New Zealand, "Population estimates," 2013, http:// www.stats.govt.nz/ /media/Statistics/browse-categories/people-and-communities/geographic-areas/urban-rural-profileupdate/population-estimates.xls.

[9] P. J. Rawlinson, The influence of the black and white tide: dairy farming, landscape and community change [Ph.D. thesis], Lincoln University, Lincoln, UK, 2011.

[10] A. C. Nelessen, Visions for a New American Dream: Process, Principles, and an Ordinance to Plan and Design Small Communities, APA Planners Press, Chicago, Ill, USA, 1994.

[11] E. E. Malizia and S. Exline, Consumer Preferences for Residential Development Alternatives, Center for Urban and Regional Studies, University of North Carolina, Chapel Hill, NC, USA, 2000.

[12] R. Kaplan, M. E. Austin, and S. Kaplan, "Open space communities: resident perceptions, nature benefits, and problems with terminology," Journal of the American Planning Association, vol. 70, no. 3, pp. 300-312, 2004.

[13] J. I. Nassauer, Z. Wang, and E. Dayrell, "What will the neighbors think? Cultural norms and ecological design," Landscape and Urban Planning, vol. 92, no. 3-4, pp. 282-292, 2009.

[14] Envision Utah, Envision Utah process: greater wastach area, 2000, http://www.fhwa.dot.gov/planning/processes/tools/toolbox/utah/index.cfm.
[15] Seattle Department of Transportation, “5th Avenue NE streetscape design project: visual preference survey results," 2001, http://www.cityofseattle.net/transportation/pdf/VisualPreferenceSurveyResults.pdf.

[16] G. G. Schultz and J. E. Searle, Understanding the Economics of Transportation Projects, Economics Research International, 2012.

[17] T. R. Herzog, S. Kaplan, and R. Kaplan, "The prediction of preference for unfamiliar urban places," Population and Environment, vol. 5, no. 1, pp. 43-59, 1982.

[18] S. Lenzholzer and N. Y. van der Wulp, "Thermal experience and perception of the built environment in Dutch urban squares," Journal of Urban Design, vol. 15, no. 3, pp. 375-401, 2010.

[19] R. Ewing, T. Schmid, R. Killingsworth, A. Zlot, and S. Raudenbush, "Relationship between urban sprawl and physical activity, obesity, and morbidity," The American Journal of Health Promotion, vol. 18, no. 1, pp. 47-57, 2003.

[20] M. C. Dunn, "Landscape with photographs: testing the preference approach to landscape evaluation," Journal of Environmental Management, vol. 4, pp. 15-26, 1976.

[21] L. M. Arthur, "Predicting scenic beauty of forest environments: some empirical tests," Forest Science, vol. 23, pp. 151-160, 1977.

[22] R. Kaplan and S. Kaplan, The Experience of Nature: A Psychological Perspective, Cambridge University Press, New York, NY, USA, 1989.

[23] J. L. Nasar, The Evaluative Image of the City, Sage, Thousand Oaks, Calif, USA, 1998.

[24] H. Sanoff, Visual Research Methods in Design, Van Nostrand Reinhold, New York, NY, USA, 1991.

[25] A. E. Stamps III and J. L. Nasar, "Design review and public preferences: effects of geographical location, public consensus, sensation seeking, and architectural styles," Journal of Environmental Psychology, vol. 17, no. 1, pp. 11-32, 1997.

[26] A. E. Stamps, Psychology and the Aesthetics of the Built Environment, Kluwer, Dordrecht, The Netherlands, 2000.

[27] A. E. Stamps III, "On shape and spaciousness," Environment and Behavior, vol. 41, no. 4, pp. 526-548, 2009.

[28] T. Tempesta, "The perception of agrarian historical landscapes: a study of the Veneto plain in Italy," Landscape and Urban Planning, vol. 97, no. 4, pp. 258-272, 2010.

[29] M. Gjerde, "Visual evaluation of urban streetscapes: how do public preferences reconcile with those held by experts," Urban Design International, vol. 16, no. 3, pp. 153-161, 2011.

[30] H. W. Schroeder, "Environmental perception rating scales: a case for simple methods of analysis," Environment and Behavior, vol. 16, no. 5, pp. 573-598, 1984.

[31] T. R. Herzog, "A cognitive analysis of preference for urban nature," Journal of Environmental Psychology, vol. 9, no. 1, pp. 27-43, 1989.

[32] P. J. Lindal and T. Hartig, "Architectural variation, building height, and the restorative quality of urban residential streetscapes," Journal of Environmental Psychology, vol. 33, pp. 26-36, 2013.

[33] E. H. Zube, D. G. Pitt, and T. W. Anderson, "Perception and prediction of scenic resources values of the Northeast," in Landscape Assessment: Values, Perceptions, and Resources, E. H. Zube, R. O. Brush, and J. G. Fabos, Eds., pp. 151-167, Dowden, Hutchinson \& Ross, Stroudsberg, Pa, USA, 1976.

[34] S. Shuttleworth, "The use of photographs as an environment presentation medium in landscape studies," Journal of Environmental Management, vol. 11, no. 1, pp. 61-76, 1980. 
[35] T. C. Daniel and M. M. Meitner, "Representational validity of landscape visualizations: the effects of graphical realism on perceived scenic beauty of forest vistas," Journal of Environmental Psychology, vol. 21, no. 1, pp. 61-72, 2001.

[36] S. B. Im, "Visual preferences in enclosed urban spaces: an exploration of a scientific approach to environmental design," Environment and Behavior, vol. 16, no. 2, pp. 235-262, 1984.

[37] A. E. Stamps, "Meta-analysis in environmental research," in Proceedings of the 28th Annual Conference of the Environmental Design Research Association Edmond, Space Design and Management for Place Making, M. S. Amiel and J. C. Vischer, Eds., pp. 114-124, Environmental Design Research Association, Edmond, Okla, USA, 1997.

[38] E. H. Zube, J. Vining, C. S. Law, and R. B. Bechtel, "Perceived urban residential quality: a cross-cultural bimodal study," Environment and Behavior, vol. 17, no. 3, pp. 327-350, 1985.

[39] J. N. Lien and G. J. Buhyoff, "Extension of visual quality models for urban forests," Journal of Environmental Management, vol. 22, no. 3, pp. 245-254, 1986.

[40] T. R. Herzog and O. L. Leverich, "Searching for legibility," Environment and Behavior, vol. 35, no. 4, pp. 459-477, 2003.

[41] M. Arriaza, J. F. Cañas-Ortega, J. A. Cañas-Madueño, and P. Ruiz-Aviles, "Assessing the visual quality of rural landscapes," Landscape and Urban Planning, vol. 69, no. 1, pp. 115-125, 2004.

[42] R. Ewing, M. R. King, S. W. Raudenbush, and O. J. Clemente, "Turning highways into main streets: two innovations in planning methodology," Journal of the American Planning Association, vol. 71, no. 3, pp. 269-282, 2005.

[43] S. W. Raudenbush and A. S. Bryk, Hierarchical Linear Models: Applications and Data Analysis Methods, Sage, Beverly Hills, Calif, USA, 2nd edition, 2002.

[44] R. Ewing, S. Handy, R. C. Brownson, O. Clemente, and E. Winston, "Identifying and measuring urban design qualities related to walkability," Journal of Physical Activity and Health, vol. 3, supplement 1, pp. S223-S240, 2006.

[45] D. H. Gustafson, R. K. Shukla, A. Delbecq, and G. W. Walster, "A comparative study of differences in subjective likelihood estimates made by individuals, interacting groups, Delphi groups, and nominal groups," Organizational Behavior and Human Performance, vol. 9, no. 2, pp. 280-291, 1973.

[46] H. A. Linstone and M. Turoff, Eds., The Delphi Method: Techniques and Applications, Addison-Wesley, New York, NY, USA, 1975.

[47] G. Cuddeback, E. Wilson, J. G. Orme, and T. Combs-Orme, "Detecting and statistically correcting sample selection bias," Journal of Social Service Research, vol. 30, no. 3, pp. 19-33, 2004.

[48] P. Marsden and J. Wright, Handbook of Survey Research, Emerald Group, London, UK, 2010.

[49] Statistics New Zealand, "2006 Census,” 2006, http://www.stats. govt.nz/Census/2006CensusHomePage.aspx.

[50] P. Lafferty, "International migration to/from Christchurch after the earthquakes," Presentation at Statistics New Zealand, 2011, http://www.population.org.nz/wp-content/uploads/2012/02/ 3b3_peter-lafferty.pdf.

[51] P. Tait and R. Cullen, Some External Costs of Dairy Farming in Canterbury, Lincoln University [Publication for Malvern Hills Protection Society Inc], 2006, http://ageconsearch.umn.edu/ handle/109595.
[52] A. E. Stamps III, "Demographic effects in environmental aesthetics: a meta-analysis," Journal of Planning Literature, vol. 14, no. 2, pp. 155-175, 1999.

[53] C. L. Regan and S. A. Horn, "To nature or not to nature: associations between environmental preferences, mood states and demographic factors," Journal of Environmental Psychology, vol. 25, no. 1, pp. 57-66, 2005. 

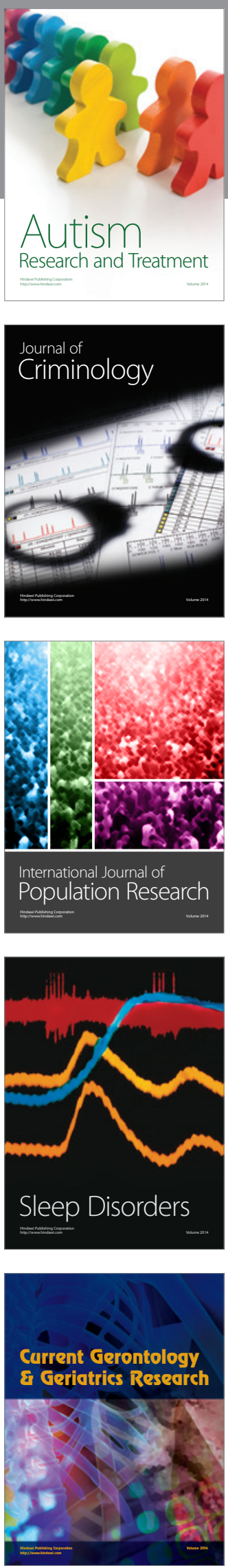
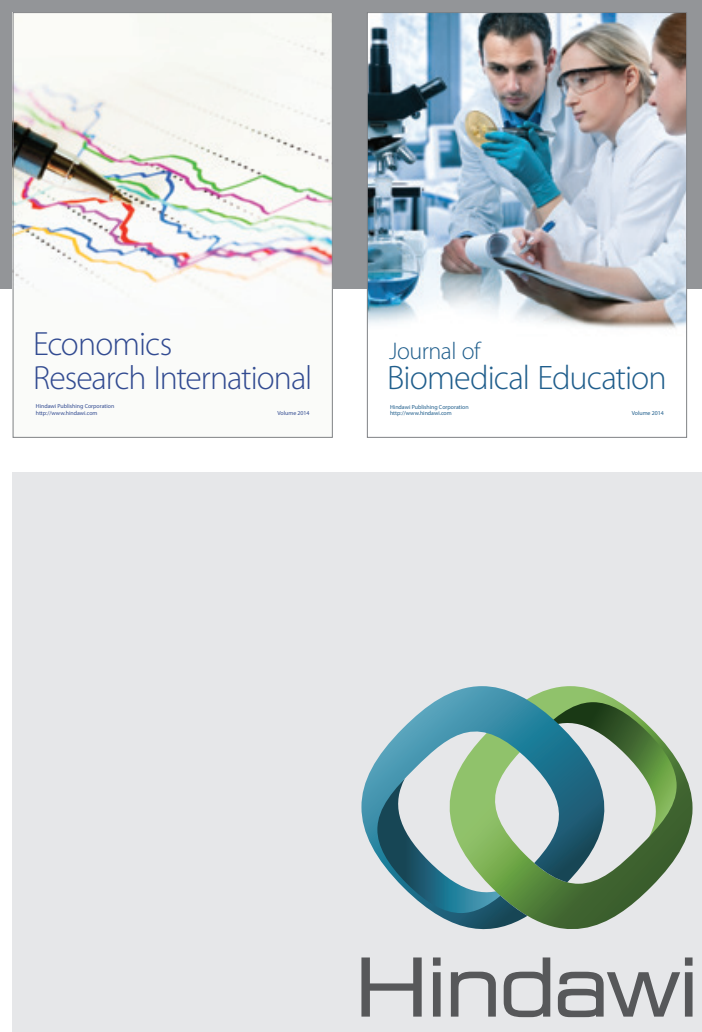

Submit your manuscripts at

http://www.hindawi.com
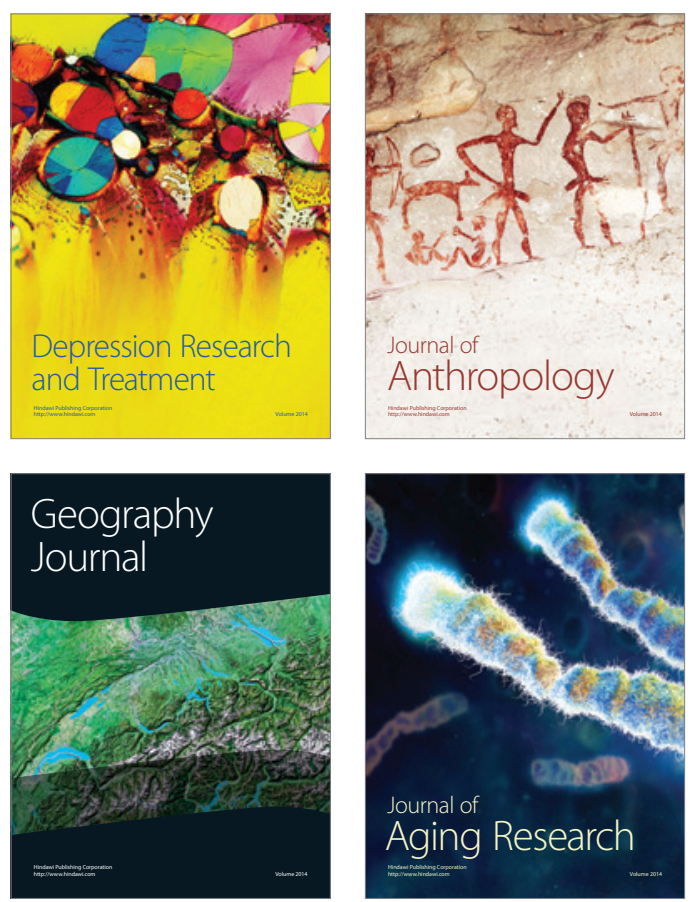
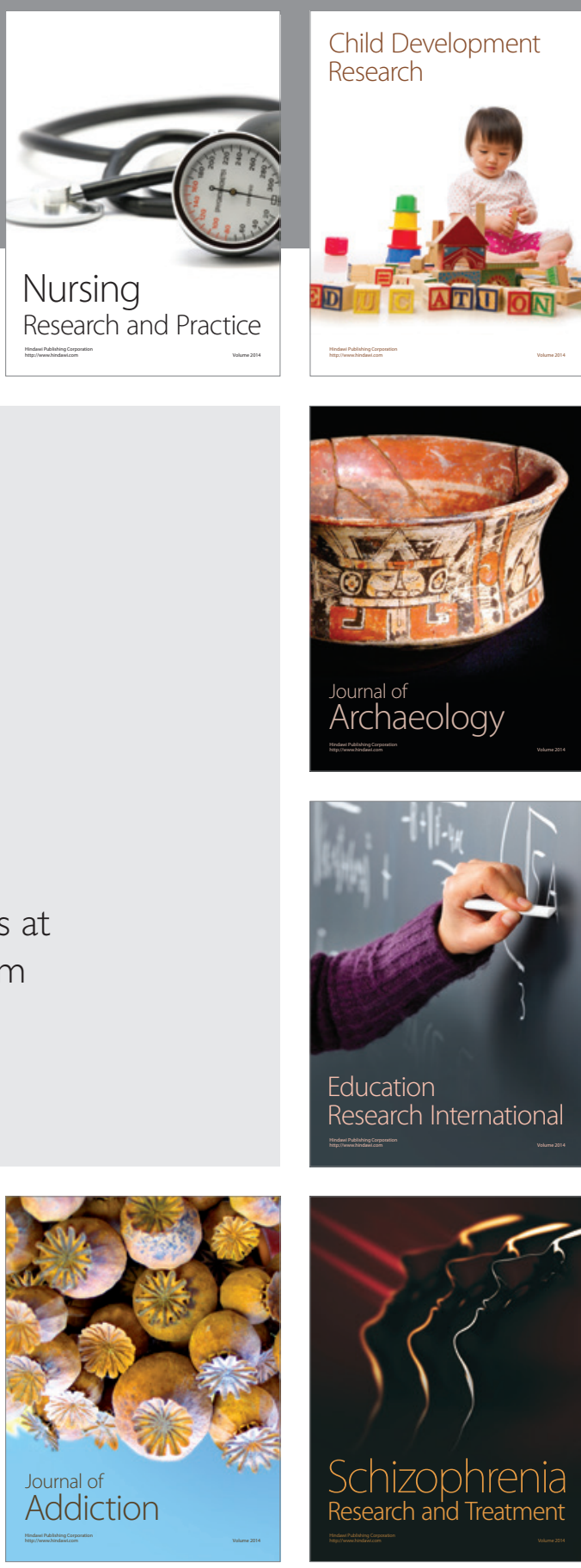

(D)
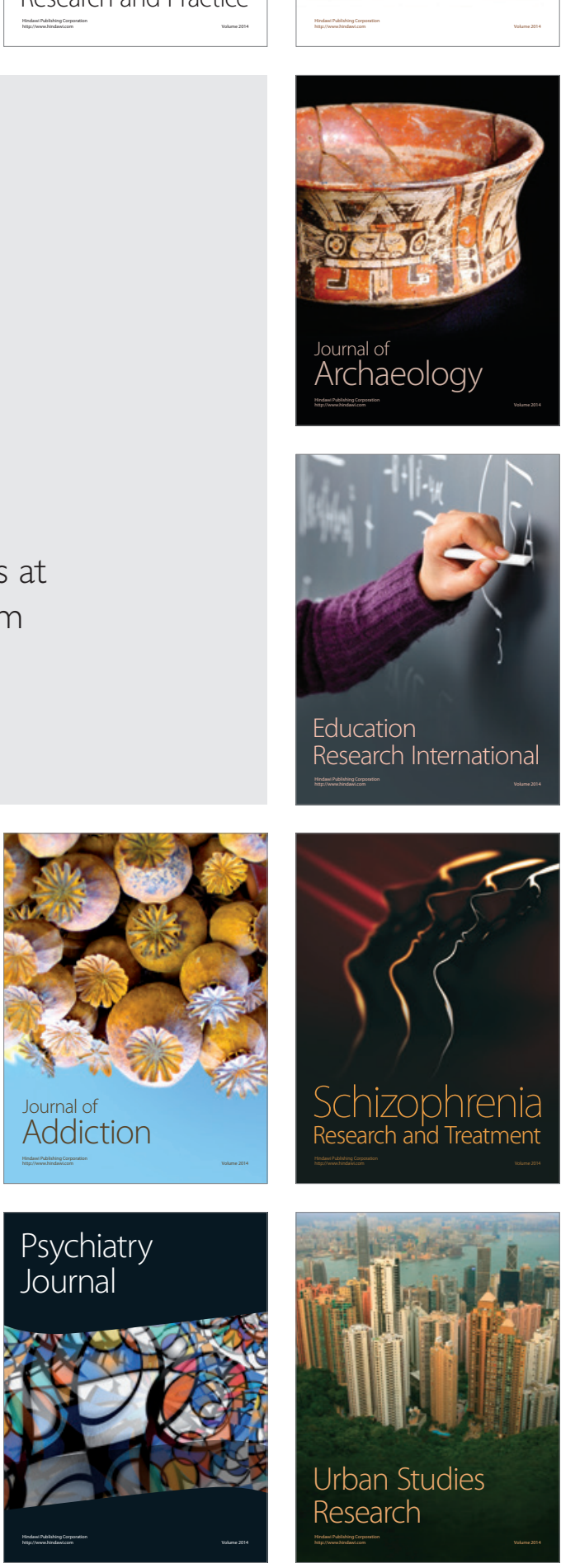